\title{
Effects of propofol combined with remifentanil anesthesia on the NO, endothelin and inflammatory cytokines in the plasma of patients with liver cirrhosis during the perioperative period
}

\author{
YONGSHENG WANG ${ }^{1}$, RONGEN QIU ${ }^{2}$, GAOYIN KONG ${ }^{1}$ and JITONG LIU ${ }^{1}$ \\ ${ }^{1}$ Department of Anesthesiology, Hunan Provincial People's Hospital, Changsha, Hunan 410005; \\ ${ }^{2}$ Department of Anesthesiology, Xiangtan Central Hospital, Xiangtan, Hunan 411413, P.R. China
}

Received November 13, 2018; Accepted February 28, 2019

DOI: $10.3892 /$ etm.2019.7367

\begin{abstract}
The effects of propofol combined with remifentanil on the nitric oxide (NO), endothelin (ET-1) and inflammatory cytokines in the plasma of patients with liver cirrhosis were investigated. A retrospective analysis of 68 patients with liver cirrhosis who underwent hepatectomy in the Hunan Provincial People's Hospital from March 2016 to July 2018 was made. According to different anesthesia methods, 30 patients anesthetized with propofol were enrolled into Group A. The other 38 patients anesthetized with propofol combined with remifentanil were enrolled into Group B, and the operation time, amount of bleeding during operation and postoperative awake time of the two groups were recorded. At three separate time-points $T_{1}$ (30 min before the anesthesia), $T_{2}$ (after the portal triad clamping), $\mathrm{T}_{3}$ (3 days after the operation), aspartate transaminase (AST) and alanine transaminase (ALT) levels in the plasma were measured by rate method, and the levels of NO, ET-1, interleukin-6 (IL-6) and tumor necrosis factor alpha (TNF- $\alpha$ ) in plasma were detected by enzyme-linked immunosorbent assay (ELISA). The plasma NO levels at the $\mathrm{T}_{2}$ time-point were significantly lower than those at the $\mathrm{T}_{1}$ and $\mathrm{T}_{3}$ time-points $(\mathrm{P}<0.05)$; at the $\mathrm{T}_{2}$ time-point, the concentrations of AST, ALT, ET-1, IL- 6 and TNF- $\alpha$ in the plasma in Group A were significantly higher than those of Group B $(\mathrm{P}<0.05)$, while the levels of plasma NO in Group A were the opposite $(\mathrm{P}<0.05)$. The anesthesia of propofol combined with remifentanil could contribute to the balance of NO/ET-1 and the inhibition of inflammatory factors during the hepatectomy operation in patients with liver cirrhosis, and help to protect the liver function of patients, reducing the incidence of liver ischemia-reperfusion injury in patients.
\end{abstract}

Correspondence to: Dr Gaoyin Kong or Dr Jitong Liu, Department of Anesthesiology, Hunan Provincial People's Hospital, 61 Jiefang West Road, Changsha, Hunan 410005, P.R. China

E-mail:kra2yz@163.com

E-mail: eui699@163.com

Key words: propofol, remifentanil, liver cirrhosis, nitric oxide, endothelin, inflammatory cytokines

\section{Introduction}

Liver cirrhosis is at the end stage of the development of chronic liver disease, arising from various etiologies such as chronic poisoning, viral hepatitis, and obstruction of hepatic venous return (1), with the long-term impact of the liver cells gradually undergoing pathological changes such as degeneration, necrosis, and liver fibrosis, and eventually developing into regenerated nodules, diffuse fibrosis of the liver, and pseudolobular shape $(2,3)$. Without effective treatment, in the long run, liver cirrhosis develops into liver decompensation and portal hypertension, causing multiple-system and multiple-organ damage in the body (4). Clinically, hepatectomy and liver transplantation are common methods for the treatment of cirrhosis (5). Fast and short-acting, propofol is a kind of intravenous anesthetic with the advantages of rapid anesthesia induction, quick recovery, and less postoperative complications (6). Remifentanil is a new type of $\mu$ opioid receptor agonist, characterized by the fast onset and significant analgesic effect (7). The combination of propofol and remifentanil can reduce the dosage and achieve sedative, analgesic and hypnotic effects (8). Hepatectomy is an important cause of the hepatic ischemia-reperfusion injury which is an important reason for liver failure during the operation (9). Mainly secreted by vascular endothelial cells, nitric oxide (NO) and endothelin (ET-1) are an active substance capable of regulating vasomotor function (10). The balance of NO/ET-1 ratio and inflammatory response are important factors in liver ischemia-reperfusion injury (11). Additionally to their sedative and anesthetic effects, propofol and remifentanil also have protective effects and immune regulating effects on the body when it suffers from ischemia-reperfusion injury $(12,13)$. In patients with liver cirrhosis who underwent hepatectomy, this study investigated the effects of propofol combined with remifentanil on the NO, ET-1 and inflammatory cytokines in the plasma of patients, with the aim of providing a reference for the anesthesia medication for patients with liver cirrhosis.

\section{Patients and methods}

General information. A retrospective analysis of 68 patients with liver cirrhosis who underwent hepatectomy in Hunan 
Provincial People's Hospital (Changsha, China) from March 2016 to July 2018 was made. According to different anesthesia methods, 30 patients anesthetized with propofol were enrolled into Group A, the other 38 patients anesthetized with propofol combined with remifentanil were enrolled into Group B. Among the patients in Group A, 22 were male and 8 were female, aged 29-65 years with a mean age of $45.94 \pm 10.67$ years, weighing $52-91 \mathrm{~kg}$ with an average body weight of $62.87 \pm 10.28 \mathrm{~kg}$. Group B contained 31 males and 7 females, aged 28-64 years, with a mean age of $47.25 \pm 9.69$ years, weighing $53-86 \mathrm{~kg}$ with an average body weight of $64.07 \pm 12.54 \mathrm{~kg}$. This study was approved by the Ethics Committee of the Hunan Provincial People's Hospital and by all the research subjects after signing the informed consent.

Inclusion and exclusion criteria. Inclusion criteria were: The patients were identified in the physical status class I or class II according to the grading standard of the American Society of Anesthesiologists (ASA) (14) and diagnosed as viral liver cirrhosis, splenomegaly, portal hypertension and hypersplenism, with a liver function grading of Child A class by the Child-Pugh classification (15); patients without history of radiotherapy, chemotherapy or steroids and opioids before surgery, and patients with complete clinical data.

Exclusion criteria were: Patients with autoimmune, endocrine, and metabolic diseases; patients with diabetes, hypertensive cerebrovascular disease; patients who received antiviral or immunosuppressive therapy, and patients with mental illness or with a family history of mental illness.

Anesthesia method. At $30 \mathrm{~min}$ before the anesthesia, all the patients were given intramuscular injection of $0.1 \mathrm{~g}$ Phenobarbital Sodium (Shanghai New Asia Pharmaceutical Co., Ltd., Shanghai, China, the code number of medical products permitted by the China Food and Drug Administration: H31020532, China), 0.5 mg Atropine (Jiangsu Fangqiang Pharmaceutical Factory Co., Ltd., Jiangsu, China, the code number of medical products permitted by the China Food and Drug Administration: H32020236, China). The upper extremity venous access was established after entering the room, and heart rate, blood pressure, $\mathrm{SpO}_{2}$, and BIS were continuously detected. All patients were dosed by intravenous target-controlled infusion. Patients in Group A were anesthetized by propofol (Beijing Fresenius Kabi Pharmaceutical Co., Ltd., Beijing, China, the code number of medical products permitted by the China Food and Drug Administration: J20070010, China), the procedure was to first perform the anesthesia induction by intravenous drip using intravenous pump with a dosage of $2.0-2.5 \mathrm{mg} / \mathrm{kg}$ and at a rate of $4 \mathrm{mg} / \mathrm{sec}$, then to maintain the intravenous infusion with a dosage of $4-12 \mathrm{mg} / \mathrm{kg}$ at a rate of $6-8 \mathrm{mg} / \mathrm{sec}$ after the induction was successful. In Group B, patients were first anesthetized by the same propofol with the same method as Group A, then were anesthetized by remifentanil (Yichang Humanwell Pharmaceutical Co., Ltd., Yichang, China, the code number of medical products permitted by the China Food and Drug Administration: H20030197, China), and the procedure was as follows: first the anesthesia induction was performed by intravenous pump with a dosage of $0.5-1 \mu / \mathrm{kg}$ at a speed of $0.5-1 \mu / \mathrm{kg} / 1 \mathrm{~min}$, then the endotracheal intubation was followed by mechanical ventilation; next, the breathing parameters were adjusted to maintain the $\mathrm{P}_{\mathrm{ET}} \mathrm{CO}_{2}$ at 30-40 mmHg. Then, the infusion of propofol and remifentanil was maintained to keep the BIS value at 40-60. All anesthetics were discontinued in the abdomen-closing, and intravenous infusion of $10 \mathrm{mg}$ of Rocuronium Bromide [Fuan Pharmaceutical (Group) Co., Ltd., Shenzhen, China, the code number of medical products permitted by the China Food and Drug Administration: H20123439, China] was given to maintain muscle relaxant.

Observation indicators. The operation time, amount of bleeding during the operation and postoperative awake time of the two groups were recorded. Venous blood $(5 \mathrm{ml})$ was separately taken at $\mathrm{T}_{1}$ (30 min before the anesthesia), $\mathrm{T}_{2}$ (after the portal triad clamping), $\mathrm{T}_{3}$ (3 days after the operation) and was stored in a low-temperature refrigerator at $-70^{\circ} \mathrm{C}$ after the plasma was separated. The aspartate transaminase (AST), alanine transaminase (ALT) were detected by the automatic biochemical analyzer [Beckman Coulter Commercial Enterprise (China) Co., Ltd., Shanghai, China] to test the liver function, according to the instructions of the instrument and AST, ALT kit rate method (Shanghai Jining Industrial Co., Ltd., Shanghai, China). The enzyme-linked immunosorbent assay (ELISA) (16) was used to measure the plasma levels of NO, ET-1, interleukin-6 (IL-6) and tumor necrosis factor alpha (TNF- $\alpha$ ). The NO and ET-1 ELISA kits were purchased from Shanghai Lanpai Biotechnology Co., Ltd. (Shanghai, China), the IL-6, TNF- $\alpha$ ELISA kits were purchased from Elabscience Biotechnology Co., Ltd (Wuhan, China). The specific detection was performed referring to the instruction manuals of the kits. The samples to be tested and the kits were taken from the refrigerator $20 \mathrm{~min}$ in advance to equilibrate with the room temperature and then the standard wells and the sample wells were set, with $50 \mu \mathrm{l}$ of the standard at different concentration in each different standard well, $10 \mu 1$ of the sample and $40 \mu \mathrm{l}$ of the sample diluent in each sample well, and none in each blank well. Horseradish peroxidase (HRP) labeled goat anti-mouse polyclonal antibody (dilution, 1:600; cat. no. E-AB-1008; Elabscience Biotechnology Co., Ltd., (Wuhan, China) (100 $\mu \mathrm{l}$ ) was added into the standard wells and sample wells which were covered with a membrane and incubated at $37^{\circ} \mathrm{C}$ for $60 \mathrm{~min}$. Next, the liquid of each well was discarded, wells were dried and washing liquid was added to each well for $1 \mathrm{~min}$, then discarding the washing liquid and drying the well, the washing procedure was repeated 5 times; after that, $50 \mu \mathrm{l}$ of working solution $\mathrm{A}$ and $50 \mu \mathrm{l}$ of working solution B were added into each well as the substrate and incubated for $15 \mathrm{~min}$ at $37^{\circ} \mathrm{C}$ in the dark. Finally, after adding $50 \mu \mathrm{l}$ of stopping solution into each well and incubating for $15 \mathrm{~min}$ at $37^{\circ} \mathrm{C}$, the automatic enzyme label analyzer (Wuxi Hiwell Diatek Instruments Co., Ltd., Wuxi, China) was used to detect the OD value of each well at the wavelength of $450 \mathrm{~nm}$, then the NO, ET-1, IL-6 and TNF- $\alpha$ contents were calculated.

Statistical analysis. Statistical analysis was performed using SPSS18.0 [Yiyun (Shanghai) Information Technology Co., Ltd., Shanghai, China]. The measurement data were expressed 
Table I. General information of patients in Groups A and B $[\mathrm{n}(\%)]($ mean $\pm \mathrm{SD})$.

\begin{tabular}{lcccr}
\hline Factors & Group A $(\mathrm{n}=30)$ & Group B $(\mathrm{n}=38)$ & $\mathrm{t} / \chi^{2}$ value & P-value \\
\hline Sex & & & 0.663 & 0.416 \\
Male & $22(73.33)$ & $31(81.58)$ & & \\
Female & $8(26.67)$ & $7(18.42)$ & & 0.598 \\
Age (years) & $45.94 \pm 10.67$ & $47.25 \pm 9.69$ & 0.529 & 0.770 \\
Glu (mmol/l) & $5.98 \pm 0.83$ & $6.03 \pm 0.57$ & 0.294 & 0.673 \\
Weight $(\mathrm{kg})$ & $62.87 \pm 10.28$ & $64.07 \pm 12.54$ & 0.424 & 0.813 \\
Smoking status & & & 0.056 & \\
Yes & $11(36.67)$ & $15(39.47)$ & & 0.623 \\
No & $19(63.33)$ & $23(60.53)$ & & \\
Drinking status & & & & \\
Yes & $18(60.00)$ & $25(65.79)$ & & \\
No & $12(40.00)$ & $13(34.21)$ & & \\
Hb $(\mathrm{g} / \mathrm{l})$ & $119.74 \pm 8.58$ & $123.68 \pm 9.56$ & 1.765 & 0.082 \\
RBC $\left(\mathrm{x} 10^{12} / \mathrm{l}\right)$ & $4.73 \pm 0.38$ & $4.67 \pm 0.49$ & 0.552 & 0.583 \\
PLT $\left(\mathrm{x} 10^{9} / \mathrm{l}\right)$ & $139.57 \pm 12.58$ & $143.08 \pm 15.09$ & 1.023 & 0.310 \\
Operation time (min) & $86.63 \pm 16.63$ & $88.48 \pm 15.94$ & 0.466 & 0.643 \\
Amount of bleeding during the operation (ml) & $361.52 \pm 40.96$ & $371.52 \pm 42.63$ & 0.977 & 0.332 \\
Awake time (sec) & $3.2 \pm 1.1$ & $3.4 \pm 0.8$ & 0.868 & 0.389 \\
\hline
\end{tabular}

Table II. Changes in the liver function indexes at $T_{1}, T_{2}$ and $T_{3}$ time-points in patients in Groups $A$ and $B(m e a n \pm S D)$.

\begin{tabular}{|c|c|c|c|c|c|c|}
\hline \multirow[b]{2}{*}{ Groups } & \multicolumn{3}{|c|}{$\mathrm{AST}(\mu \mathrm{mol} / \mathrm{l})$} & \multicolumn{3}{|c|}{$\operatorname{ALT}(\mu \mathrm{mol} / \mathrm{l})$} \\
\hline & $\mathrm{T}_{1}$ & $\mathrm{~T}_{2}$ & $\mathrm{~T}_{3}$ & $\mathrm{~T}_{1}$ & $\mathrm{~T}_{2}$ & $\mathrm{~T}_{3}$ \\
\hline Group A $(n=30)$ & $30.24 \pm 4.36$ & $61.38 \pm 2.52^{\mathrm{a}}$ & $31.83 \pm 2.74$ & $31.59 \pm 2.64$ & $67.53 \pm 4.41^{\mathrm{a}}$ & $32.74 \pm 2.95$ \\
\hline Group B $(n=38)$ & $30.79 \pm 2.55$ & $45.63 \pm 3.96^{\mathrm{a}, \mathrm{b}}$ & $32.08 \pm 1.55$ & $31.47 \pm 2.82$ & $48.6 \pm 1.77^{\mathrm{a}, \mathrm{b}}$ & $32.21 \pm 2.48$ \\
\hline t value & 0.650 & 18.950 & 0.475 & 0.179 & 24.150 & 0.805 \\
\hline P-value & 0.518 & $<0.001$ & 0.636 & 0.858 & $<0.001$ & 0.424 \\
\hline
\end{tabular}

${ }^{\mathrm{a}} \mathrm{P}<0.05$ when compared with $\mathrm{T}_{1}$ time-point; ${ }^{\mathrm{b}} \mathrm{P}<0.05$ when compared with Group $\mathrm{A}$ at $\mathrm{T}_{2}$ time-point.

as the mean \pm the standard deviation (mean $\pm \mathrm{SD}$ ), and the enumeration data were expressed as the number/percentage (n/\%). Chi-square test was used to compare the enumeration data between groups, and the t-test was used to compare the measurement data between groups. One-way ANOVA with Least Significant Difference post hoc test was used to compare the means between multiple groups. The repeated measures for variance analysis was used to compare the data of multiple time-points. SNK test was used for comparison between two groups. Statistical difference was set at $\mathrm{P}<0.05$.

\section{Results}

General information of the two groups of patients. No statistical difference was detected between Groups A and B in terms of general clinical baseline data including sex, age, blood glucose (Glu), body weight, smoking status, drinking status, hemoglobin $(\mathrm{Hb})$, red blood cell (RBC) count, platelet (PLT) count, operative time, amount of bleeding during the operation, awake time (all P>0.05) (Table I).

Changes in the liver function indexes in the two groups during the perioperative period. No significant difference was shown in the plasma AST and ALT levels between Groups A and B at $\mathrm{T}_{1}$ and $\mathrm{T}_{3}$ time-points $(\mathrm{P}>0.05)$. In both Groups $\mathrm{A}$ and $\mathrm{B}$, the plasma levels of AST and ALT at the $\mathrm{T}_{2}$ time-point were significantly higher than those at the $\mathrm{T}_{1}$ and $\mathrm{T}_{3}$ time-points $(\mathrm{P}<0.05)$, and the plasma AST and ALT levels at the $\mathrm{T}_{2}$ time-point in Group A were significantly higher than that in Group B $(\mathrm{P}<0.05)$ (Table II).

Changes of plasma NO content in the two groups during the perioperative period. The plasma NO content of patients in Group $A$ at the $T_{1}, T_{2}$, and $T_{3}$ time-points were 


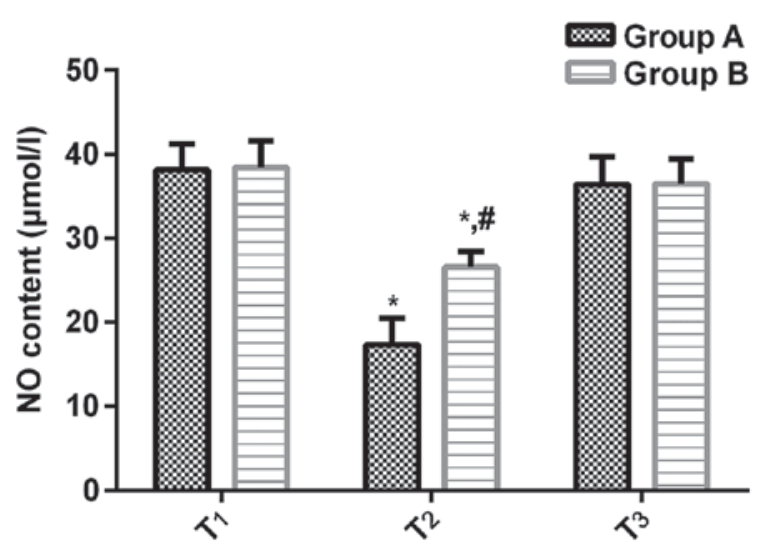

Figure 1. Changes of plasma NO content in Groups A and B during the perioperative period. The ELISA results showed that no significant difference existed in the plasma NO content between Groups A and B at the $T_{1}$ and $T_{3}$ time-points $(\mathrm{P}>0.05)$; the plasma NO levels in both Groups A and B at the $\mathrm{T}_{2}$ time-point were significantly lower than that at the $\mathrm{T}_{1}$ and $\mathrm{T}_{3}$ time-points $(\mathrm{P}<0.05)$; and that the plasma $\mathrm{NO}$ content in Group A was significantly lower than that of Group B at the $\mathrm{T}_{2}$ time-point $(\mathrm{P}<0.05)$. ${ }^{*} \mathrm{P}<0.05$ compared with $\mathrm{T}_{1}$ time-point; ${ }^{\mathrm{P}} \mathrm{P}<0.05$ compared with Group $\mathrm{A}$ at the $\mathrm{T}_{2}$ time-point.

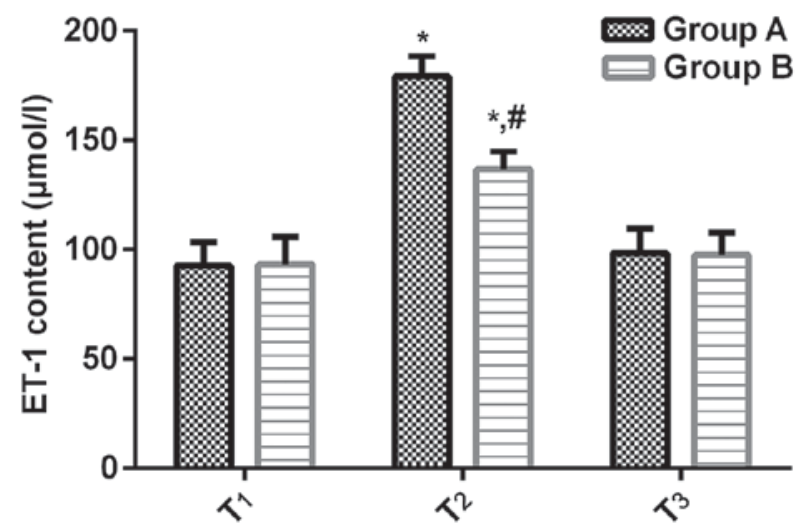

Figure 2. Changes in the plasma ET-1 levels in Group A and Group B during the perioperative period. The ELISA results showed that no significant difference in the plasma ET-1 levels between Groups A and B presented at the $\mathrm{T}_{1}$ and $\mathrm{T}_{3}$ time-points $(\mathrm{P}>0.05)$; the plasma ET-1 levels at the $\mathrm{T}_{2}$ time-point were significantly higher than those at the $\mathrm{T}_{1}$ and $\mathrm{T}_{3}$ time-points $(\mathrm{P}<0.05)$, and the plasma ET-1 levels at the $\mathrm{T}_{2}$ time-point in Group A were significantly higher than that in Group $\mathrm{B}(\mathrm{P}<0.05)$. ${ }^{\mathrm{P}}<0.05$ compared with $\mathrm{T}_{1}$ time-point; ${ }^{\#} \mathrm{P}<0.05$ compared with Group $\mathrm{A}$ at the $\mathrm{T}_{2}$ time-point.

$38.13 \pm 3.05,17.34 \pm 3.16$ and $36.41 \pm 3.28 \mu \mathrm{mol} / 1$, respectively, while the plasma NO content of patients in Group B at the $\mathrm{T}_{1}, \mathrm{~T}_{2}$ and $\mathrm{T}_{3}$ time-points were $38.43 \pm 3.18,26.59 \pm 1.86$ and $36.49 \pm 2.96 \mu \mathrm{mol} / 1$, respectively, showing that no significant difference existed in the plasma NO content between Groups $\mathrm{A}$ and $\mathrm{B}$ at the $\mathrm{T}_{1}$ and $\mathrm{T}_{3}$ time-points $(\mathrm{P}>0.05)$; the plasma NO levels in both Groups $\mathrm{A}$ and $\mathrm{B}$ at the $\mathrm{T}_{2}$ time-point were significantly lower than that at the $\mathrm{T}_{1}$ and $\mathrm{T}_{3}$ time-points $(\mathrm{P}<0.05)$; and that the plasma NO content in Group A was significantly lower than that of Group $\mathrm{B}$ at the $\mathrm{T}_{2}$ time-point $(\mathrm{P}<0.05)$ (Fig. 1).

Changes of plasma ET-1 levels in the two groups during the perioperative period. According to the plasma ET-1 levels in Group $\mathrm{A}$ at the $\mathrm{T}_{1}, \mathrm{~T}_{2}$ and $\mathrm{T}_{3}$ time-points $(92.57 \pm 10.52$, $179.05 \pm 9.27$ and $98.24 \pm 11.57 \mu \mathrm{mol} / \mathrm{l})$, and the plasma ET-1

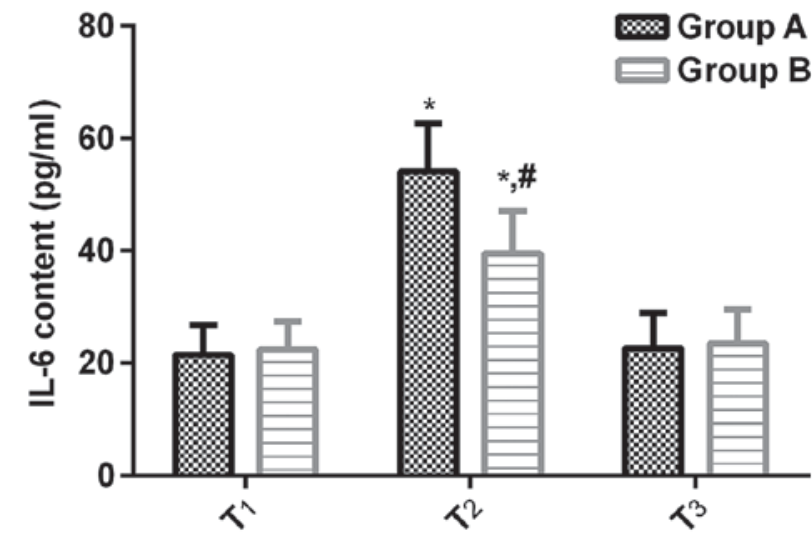

Figure 3. Changes in the plasma IL-6 levels in Groups A and B during the perioperative period. The ELISA results showed that no significant difference was found in the plasma IL-6 levels between Groups A and B at the $\mathrm{T}_{1}$ and $\mathrm{T}_{3}$ time-points $(\mathrm{P}>0.05)$. the plasma IL-6 levels at the $\mathrm{T}_{2}$ time-point were significantly higher than at the $\mathrm{T}_{1}$ and $\mathrm{T}_{3}$ time-points $(\mathrm{P}<0.05)$, and the plasma IL-6 levels at the $T_{2}$ time-point in Group A were significantly higher than that in Group $\mathrm{B}(\mathrm{P}<0.05)$. $\mathrm{P}<0.05$ compared with $\mathrm{T}_{1}$ time-point; ${ }^{\#} \mathrm{P}<0.05$ compared with Group $\mathrm{A}$ at the $\mathrm{T}_{2}$ time-point.

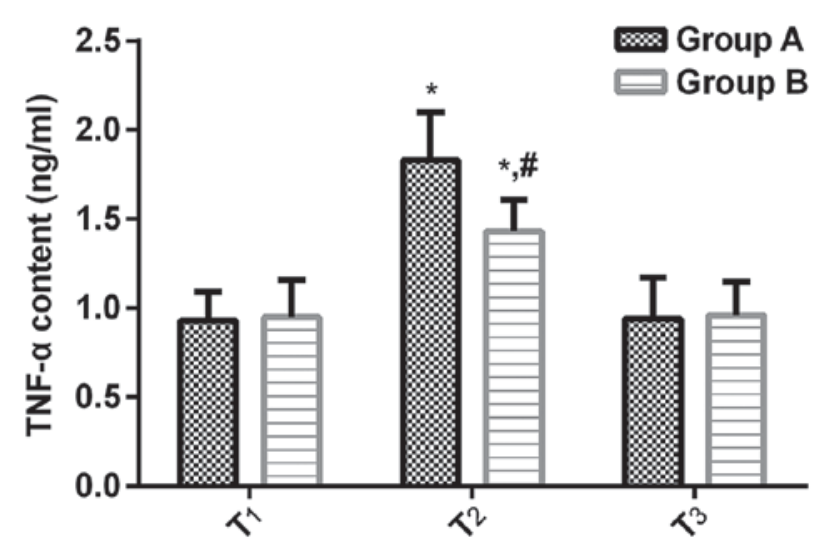

Figure 4. Changes in plasma TNF- $\alpha$ levels in Groups A and B during the perioperative period. The ELISA results showed that no significant difference in the plasma TNF- $\alpha$ levels between Groups A and B surfaced at the T and $\mathrm{T}_{3}$ time-points $(\mathrm{P}>0.05)$; the plasma TNF- $\alpha$ levels at the $\mathrm{T}_{2}$ time-point were significantly higher than at the $\mathrm{T}_{1}$ and $\mathrm{T}_{3}$ time-points $(\mathrm{P}<0.05)$, and the plasma TNF- $\alpha$ levels at the $\mathrm{T}_{2}$ time-point in Group A were significantly higher than that in Group $\mathrm{B}(\mathrm{P}<0.05)$. ${ }^{*} \mathrm{P}<0.05$ compared with $\mathrm{T}_{1} ;{ }^{*} \mathrm{P}<0.05$ compared with group $\mathrm{A}$ at $\mathrm{T}_{2}$.

levels in Group B at the $\mathrm{T}_{1}, \mathrm{~T}_{2}$ and $\mathrm{T}_{3}$ time-points $(93.15 \pm 12.63$, $136.59 \pm 8.09$, and $97.45 \pm 10.28 \mu \mathrm{mol} / \mathrm{l})$, no significant difference in the plasma ET-1 levels between Groups A and B was presented at the $\mathrm{T}_{1}$ and $\mathrm{T}_{3}$ time-points $(\mathrm{P}>0.05)$; the plasma ET-1 levels at the $\mathrm{T}_{2}$ time-point were significantly higher than those at the $\mathrm{T}_{1}$ and $\mathrm{T}_{3}$ time-points $(\mathrm{P}<0.05)$, and the plasma ET-1 levels at the $\mathrm{T}_{2}$ time-point in Group A were significantly higher than those in Group B $(\mathrm{P}<0.05)$ (Fig. 2).

Changes of plasma IL-6 levels in the two groups during the perioperative period. The plasma IL-6 levels of patients in Group $A$ at the $\mathrm{T}_{1}, \mathrm{~T}_{2}$ and $\mathrm{T}_{3}$ time-points were $21.53 \pm 5.23$, $54.15 \pm 8.63$ and $22.69 \pm 6.18 \mathrm{pg} / \mathrm{ml}$, respectively, and the plasma IL-6 levels of patients in Group B at the $\mathrm{T}_{1}, \mathrm{~T}_{2}$ and $\mathrm{T}_{3}$ time-points were $22.41 \pm 5.08,39.57 \pm 7.51$ and $23.47 \pm 6.15 \mathrm{pg} / \mathrm{ml}$, respectively. No significant difference was found in the plasma IL-6 
levels between Groups $\mathrm{A}$ and $\mathrm{B}$ at the $\mathrm{T}_{1}$ and $\mathrm{T}_{3}$ time-points $(\mathrm{P}>0.05)$. The plasma IL-6 levels at the $\mathrm{T}_{2}$ time-point were significantly higher than at the $\mathrm{T}_{1}$ and $\mathrm{T}_{3}$ time-points $(\mathrm{P}<0.05)$, and the plasma IL-6 levels at the $\mathrm{T}_{2}$ time-point in Group A were significantly higher than that in Group B $(\mathrm{P}<0.05)$ (Fig. 3).

Changes of plasma TNF- $\alpha$ levels in the two groups of patients during the perioperative period. According to the plasma TNF- $\alpha$ levels in Group $A$ at the $T_{1}, T_{2}$ and $T_{3}$ time-points $(0.93 \pm 0.16,1.83 \pm 0.27$ and $0.94 \pm 0.23 \mathrm{ng} / \mathrm{ml})$, and the plasma TNF- $\alpha$ levels in Group B at the $\mathrm{T}_{1}, \mathrm{~T}_{2}$ and $\mathrm{T}_{3}$ time-points $(0.95 \pm 0.21,1.43 \pm 0.18$ and $0.96 \pm 0.19 \mathrm{ng} / \mathrm{ml})$, no significant difference in the plasma TNF- $\alpha$ levels between Groups A and $B$ surfaced at the $T_{1}$ and $T_{3}$ time-points $(P>0.05)$; the plasma TNF- $\alpha$ levels at the $\mathrm{T}_{2}$ time-point were significantly higher than at the $\mathrm{T}_{1}$ and $\mathrm{T}_{3}$ time-points $(\mathrm{P}<0.05)$, and the plasma TNF- $\alpha$ levels at the $\mathrm{T}_{2}$ time-point in Group A were significantly higher than that in Group B $(\mathrm{P}<0.05)$ (Fig. 4).

\section{Discussion}

A commonly chosen operation for patients with cirrhosis in the clinic, hepatectomy requires to block the hepatic vascular during the surgery with the consideration to reduce the amount of bleeding, which brings problems since the re-opening of hepatic vascular after the surgery may cause ischemia-reperfusion injury of the liver, impaired vascular endothelial function and liver function, affecting the liver's regeneration ability after the surgery $(17,18)$. Previous studies have shown that NO/ET-1 ratio and inflammatory response are closely related to hepatic ischemia-reperfusion injury, which can reflect the liver function of the body $(19,20)$. Therefore, to protect the vascular endothelial function and relieve the inflammatory response without interfering with the smooth operation is of great help to improve the prognosis of patients with cirrhosis.

Characterized by quick effect, short duration, and stable awaking status and less adverse reactions, the powerful and effective anesthetic propofol, has been widely used in clinical practice (21). Remifentanil, a fentanyl opioid receptor agonist that can be rapidly absorbed by intravenous administration, has a synergistic effect with inhaled anesthetics, hypnotics, and benzodiazepines, and its dose is closely related to analgesic effects $(22,23)$. At present, the mechanism of action of propofol and remifentanil in liver surgery has not been elucidated. The study made by Hao et al (24) showed that propofol could prevent the apoptosis of liver cells and reduce ischemia-reperfusion injury in rats. Xu et al (25) and Liu et al (26) considered that propofol and remifentanil had protective effects on the hepatic ischemia-reperfusion injury, which could improve the liver function and liver microcirculation.

As active substances secreted by vascular endothelial cells, both NO and ET-1 have a function of regulating vasomotion. In the early stage of hepatic ischemia-reperfusion injury, hepatocytes are in an ischemic and hypoxic environment, where the intracellular calcium concentration gradually increases to push the endothelial cells to secrete a large amount of ET-1 that can worsen vasoconstriction and cause secondary damage to the liver cells as the liver microcirculation is disturbed $(27,28)$. The decrease of NO, reducing the function of
ET-1 by promoting the secretion and synthesis of ET-1 through feedback, can aggravate the vasoconstriction, which further damages the liver cells and causes liver ischemia-reperfusion injury (29). According to the results of this study, the plasma NO levels in both Groups $\mathrm{A}$ and $\mathrm{B}$ at the $\mathrm{T}_{2}$ time-point were significantly lower than that at the $\mathrm{T}_{1}$ and $\mathrm{T}_{3}$ time-points, while the ET-1 level was the opposite; at the $\mathrm{T}_{2}$ time-point, the plasma NO content in Group A was significantly lower than that of Group B, but the plasma ET-1 content in Group A was significantly higher than that of Group B, indicating that the balance of the ratio of NO/ET-1 was significantly broken during the hepatolobectomy surgery, and the disorder of the ratio of NO/ET-1 was significantly relieved after the anesthesia with propofol and remifentanil.

Hepatectomy can cause hepatic ischemia-reperfusion injury, which manifests as the release of a large number of inflammatory cytokines, the hepatocyte degeneration and necrosis, and a large number of leukocyte infiltrations (30). IL- 6 and TNF- $\alpha$, the most active pro-inflammatory cytokines currently studied, mainly released by monocytes, can cause a strong inflammatory reaction in the body, resulting in secondary damage to impaired organs $(31,32)$. The study by Taub et al (33) showed that within a few minutes after the hepatectomy, IL- 6 and TNF- $\alpha$ could be released from the non-parenchymal liver, causing liver inflammation. The results of this study showed that plasma levels of IL- 6 and TNF- $\alpha$ in both Groups $\mathrm{A}$ and $\mathrm{B}$ at the $\mathrm{T}_{2}$ time-point were significantly higher than those at the $\mathrm{T}_{1}$ and $\mathrm{T}_{3}$ time-points, and the levels of plasma IL- 6 and TNF- $\alpha$ at the $T_{2}$ time in Group A were significantly higher than those in Group B, suggesting that propofol and remifentanil could inhibit the significant inflammatory response occurred during the hepatectomy operation. As shown in the this study, in both Groups A and B, the plasma levels of AST and ALT at the $\mathrm{T}_{2}$ time-point were significantly higher than those at the $T_{1}$ and $T_{3}$ time-points, and the plasma AST and ALT levels at the $T_{2}$ time-point in Group A were significantly higher than that in Group B, suggesting that propofol and remifentanil could prevent the liver function from the influence of hepatectomy to a certain degree, which was similar to the conclusion of the study by Poon et al (34) that hepatectomy might affect liver function in patients.

The research subjects of this study were selected in strict accordance with the inclusion and exclusion criteria. The general clinical baseline data of patients between the two groups were not significantly different in such terms as sex, age, Glu, body weight, smoking status, drinking status, $\mathrm{Hb}$, RBC count, PLT count, operation time, amount of bleeding during the operation, and awake time to ensure the rigor and reliability of this study. Limitations of this study were that no follow-up of the prognosis of patients was performed and the specific regulatory mechanisms for propofol and remifentanil were not elucidated. Thus, future studies should extend the study time to clarify the specific regulatory mechanisms for propofol and remifentanil.

In summary, the anesthesia of propofol combined with remifentanil could contribute to the balance of NO/ET-1 and the inhibition of inflammatory factors during the hepatectomy operation in patients with liver cirrhosis, and help to protect the liver function of patients, and reduce the incidence of liver ischemia-reperfusion injury in patients. 


\section{Acknowledgements}

Not applicable.

\section{Funding}

This study was supported by Research Foundation of Health Commission of Hunan Province (grant no. B2019065).

\section{Availability of data and materials}

The datasets used and/or analyzed during the present study are available from the corresponding author on reasonable request.

\section{Authors' contributions}

YW was involved in the writing of the manuscript. YW and RQ performed ELISA. GK collected the general data of the patients. YW and JL analyzed and interpreted the patient data regarding the NO, endothelin and inflammatory cytokines. All authors read and approved the final manuscript.

\section{Ethics approval and consent to participate}

The study was approved by the Ethics Committee of Hunan Provincial People's Hospital (Changsha, China). Patients who participated in this study, had complete clinical data. Signed informed consents were obtained from the patients or guardians.

\section{Patient consent for publication}

Not applicable.

\section{Competing interests}

The authors declare that they have no competing interests.

\section{References}

1. Morales BP, Planas R, Bartoli R, Morillas RM, Sala M, Cabré E, Casas I and Masnou H: Early hospital readmission in decompensated cirrhosis: Incidence, impact on mortality, and predictive factors. Dig Liver Dis 49: 903-909, 2017.

2. Schuppan D and Afdhal NH: Liver cirrhosis. Lancet 371: 838-851, 2008.

3. Durand F, Buyse S, Francoz C, Laouénan C, Bruno O, Belghiti J, Moreau R, Vilgrain V and Valla D: Prognostic value of muscle atrophy in cirrhosis using psoas muscle thickness on computed tomography. J Hepatol 60: 1151-1157, 2014.

4. González-González JA, García-Compean D, Vázquez-Elizondo G, Garza-Galindo A, Jáquez-Quintana JO and Maldonado-Garza H: Nonvariceal upper gastrointestinal bleeding in patients with liver cirrhosis. Clinical features, outcomes and predictors of in-hospital mortality. A prospective study. Ann Hepatol 10: 287-295, 2011.

5. Cheung TT, Dai WC, Tsang SH, Chan AC, Chok KS, Chan SC and Lo CM: Pure laparoscopic hepatectomy versus open hepatectomy for hepatocellular carcinoma in 110 patients with liver cirrhosis: A propensity analysis at a single center. Ann Surg 264: 612-620, 2016

6. Girdler NM, Rynn D, Lyne JP and Wilson KE: A prospective randomised controlled study of patient-controlled propofol sedation in phobic dental patients. Anaesthesia 55: 327-333, 2000

7. Comelon M, Raeder J, Stubhaug A, Nielsen CS, Draegni T and Lenz H: Gradual withdrawal of remifentanil infusion may prevent opioid-induced hyperalgesia. Br J Anaesth 116: 524-530, 2016.
8. Hannivoort LN, Vereecke HE, Proost JH, Heyse BE, Eleveld DJ, Bouillon TW, Struys MM and Luginbühl M: Probability to tolerate laryngoscopy and noxious stimulation response index as general indicators of the anaesthetic potency of sevoflurane, propofol, and remifentanil. Br J Anaesth 116: 624-631, 2016.

9. Olthof PB, van Golen RF, Meijer B, van Beek AA, Bennink RJ, Verheij J, van Gulik TM and Heger M: Warm ischemia timedependent variation in liver damage, inflammation, and function in hepatic ischemia/reperfusion injury. Biochim Biophys Acta Mol Basis Dis 1863: 375-385, 2017.

10. Vasiljevic B, Maglajlic-Djukic S, Gojnic M, Stankovic S, Ignjatovic $S$ and Lutovac D: New insights into the pathogenesis of perinatal hypoxic-ischemic brain injury. Pediatr Int 53: 454-462, 2011.

11. Zhang Y, Chen Z, Feng N, Tang J, Zhao X, Liu C, Xu H and Zhang M: Protective effect of propofol preconditioning on ischemia-reperfusion injury in human hepatocyte. J Thorac Dis 9: 702-710, 2017.

12. Losada DM, Souza ME, Jordani MC, Picinato MA, Fina CF, Feres O, Michelone PR and Silva OC: Hyperbaric oxygen therapy and ischemia and reperfusion: A valuable association to attenuate ischemic lesion and hepatic reperfusion. Acta Cir Bras 28: 126-130, 2013.

13. Pikwer A, Castegren M, Namdar S, Blennow K, Zetterberg $\mathrm{H}$ and Mattsson N: Effects of surgery and propofol-remifentanil total intravenous anesthesia on cerebrospinal fluid biomarkers of inflammation, Alzheimer's disease, and neuronal injury in humans: A cohort study. J Neuroinflammation 14: 193, 2017.

14. Khan AS, Williams G, Woolsey C, Liu J, Fields RC, Doyle MMB, Hawkins WG and Strasberg SM: Flange gastroenterostomy results in reduction in delayed gastric emptying after standard pancreaticoduodenectomy: A prospective cohort study. J Am Coll Surg 225: 498-507, 2017

15. Au KP, Chan SC, Chok KS, Chan AC, Cheung TT, Ng KK and Lo CM: Child-Pugh parameters and platelet count as an alternative to ICG test for assessing liver function for major hepatectomy. HPB Surg 2017: 2948030, 2017.

16. Ndongo-Thiam N, Clement A, Pin JJ, Razanajaona-Doll D and Miossec P: Negative association between autoantibodies against IL-17, IL-17/anti-IL-17 antibody immune complexes and destruction in rheumatoid arthritis. Ann Rheum Dis 75: 1420-1422, 2016.

17. Simillis C, Robertson FP, Afxentiou T, Davidson BR and Gurusamy KS: A network meta-analysis comparing perioperative outcomes of interventions aiming to decrease ischemia reperfusion injury during elective liver resection. Surgery 159: 1157-1169, 2016.

18. Ohana G, Cohen S, Rath-Wolfson L and Fishman P: A3 adenosine receptor agonist, $\mathrm{CF} 102$, protects against hepatic ischemia/reperfusion injury following partial hepatectomy. Mol Med Rep 14: 4335-4341, 2016.

19. Ratti F, Pulitanò C, Catena M, Paganelli M and Aldrighetti L: Serum levels of endothelin-1 after liver resection as an early predictor of postoperative liver failure. A prospective study. Hepatol Res 46: 529-540, 2016.

20. Wiggers JK, van Golen RF, Verheij J, Dekker AM, van Gulik TM and Heger M: Atorvastatin does not protect against ischemia-reperfusion damage in cholestatic rat livers. BMC Surg 17: 35, 2017.

21. Johnston DF, Stafford M, McKinney M, Deyermond R and Dane K: Peripheral nerve blocks with sedation using propofol and alfentanil target-controlled infusion for hip fracture surgery: A review of 6 years in use. J Clin Anesth 29: 33-39, 2016.

22. Freeman LM, Bloemenkamp KW, Franssen MT, Papatsonis DN, Hajenius PJ, Hollmann MW, Woiski MD, Porath M, van den Berg HJ, van Beek E, et al: Patient controlled analgesia with remifentanil versus epidural analgesia in labour: Randomised multicentre equivalence trial. BMJ 350: h846, 2015.

23. Eleveld DJ, Proost JH, Vereecke H, Absalom AR, Olofsen E, Vuyk J and Struys MMRF: An allometric model of remifentanil pharmacokinetics and pharmacodynamics. Anesthesiology 126: 1005-1018, 2017.

24. Hao W, Zhao ZH, Meng QT, Tie ME, Lei SQ and Xia ZY: Propofol protects against hepatic ischemia/reperfusion injury via miR-133a-5p regulating the expression of MAPK6. Cell Biol Int 41: 495-504, 2017.

25. Xu Z, Yu J, Wu J, Qi F, Wang H, Wang Z and Wang Z: The effects of two anesthetics, propofol and sevoflurane, on liver ischemia/ reperfusion injury. Cell Physiol Biochem 38: 1631-1642, 2016.

26. Liu X, Pan Z, Su D, Yang Z, Zheng B, Wang X and Tian J: Remifentanil ameliorates liver ischemia-reperfusion injury through inhibition of interleukin-18 signaling. Transplantation 99: 2109-2117, 2015. 
27. Gogus N, Akan B, Bayrakci S, Girgin G and Baydar M: The effects of a small-dose ketamine-propofol combination on tourniquet-induced ischemia-reperfusion injury during arthroscopic knee surgery. J Clin Anesth 26: 46-51, 2014.

28. Kumar A, Aggarwal R, Naik SR, Saraswat V, Ghoshal UC and Naik S: Hepatitis E virus is responsible for decompensation of chronic liver disease in an endemic region. Indian J Gastroenterol 23: 59-62, 2004.

29. Marasciulo FL, Montagnani M and Potenza MA: Endothelin-1: The yin and yang on vascular function. Curr Med Chem 13: 1655-1665, 2006.

30. Lentsch AB, Kato A, Yoshidome H, McMasters KM and Edwards MJ: Inflammatory mechanisms and therapeutic strategies for warm hepatic ischemia/reperfusion injury. Hepatology 32: 169-173, 2000

31. Charrad R, Berraïes A, Hamdi B, Ammar J, Hamzaoui K and Hamzaoui A: Anti-inflammatory activity of IL-37 in asthmatic children: Correlation with inflammatory cytokines TNF- $\alpha$, IL- $\beta$, IL-6 and IL-17A. Immunobiology 221: 182-187, 2016.
32. Thimmulappa RK, Lee H, Rangasamy T, Reddy SP, Yamamoto M, Kensler TW and Biswal S: Nrf2 is a critical regulator of the innate immune response and survival during experimental sepsis. J Clin Invest 116: 984-995, 2006.

33. Taub R, Greenbaum LE and Peng Y: Transcriptional regulatory signals define cytokine-dependent and -independent pathways in liver regeneration. Semin Liver Dis 19: 117-127, 1999.

34. Poon RT, Fan ST, Lo CM, Liu CL and Wong J: Long-term survival and pattern of recurrence after resection of small hepatocellular carcinoma in patients with preserved liver function: Implications for a strategy of salvage transplantation. Ann Surg 235: 373-382, 2002.

This work is licensed under a Creative Commons Attribution-NonCommercial-NoDerivatives 4.0 International (CC BY-NC-ND 4.0) License. 